\title{
miR-29 promotes the proliferation of cultured rat neural stem/progenitor cells via the PTEN/AKT signaling pathway
}

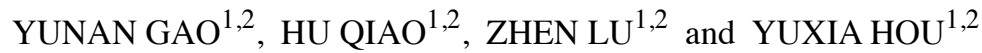 \\ ${ }^{1}$ Key Laboratory of Shaanxi Province for Craniofacial Precision Medicine Research, \\ College of Stomatology, Xi'an Jiaotong University; ${ }^{2}$ Department of Orthodontics, \\ Stomatological Hospital of Xi'an Jiaotong University, Xi'an, Shaanxi 710004, P.R. China
}

Received October 31, 2018; Accepted April 26, 2019

DOI: $10.3892 / \mathrm{mmr} .2019 .10445$

\begin{abstract}
Neural stem/progenitor cells (NSPCs) are self-renewing, multipotent cells and remain in the human brain throughout an individual's lifetime. NSPCs are activated by brain damage and contribute towards repair and motor function recovery in the central nervous system (CNS). It was previously reported that miR-29 was involved in regulating proliferation, differentiation and survival in hepatocellular carcinoma, and osteoblast and mantle cell lymphoma; however, the effects of miR-29 on NSPCs remain unclear. In the present study, it was demonstrated via Cell Counting Kit-8 assays that overexpression of miR-29 promoted the viability of NPSCs, and downregulated the expression of phosphatase and tensin homologue deleted on chromosome 10 (PTEN) protein. Additionally, treatment with a PTEN-specific inhibitor (VO-OHpic trihydrate) abolished the effects of the miR-29 inhibitor on PTEN expression, as determined via western blotting. Flow cytometry and 5-bromo-2-deoxyuridine (BrdU) staining revealed that overexpression of miR-29 further promoted the proliferation of NSPCs; however, knocking down miR-29 inhibited cell proliferation. VO-OHpic trihydrate reversed the effects of miR-29 knockdown on cell proliferation. Furthermore, it was observed that overexpression of miR-29 increased the phosphorylation levels of AKT. Collectively, the results indicated that overexpression of miR-29 promoted the proliferation of cultured rat NSPCs and decreased the expression of PTEN protein, and that the activation of Akt may be a potential underlying mechanism. The
\end{abstract}

Correspondence to: Dr Yuxia Hou, Key Laboratory of Shaanxi Province for Craniofacial Precision Medicine Research, College of Stomatology, Xi'an Jiaotong University, 98 Xiwu Road, Xi'an, Shaanxi 710004, P.R. China

E-mail: 369hyx@163.com

Abbreviations: CNS, central nervous system; NSPCs, neural stem/progenitor cells; PTEN, phosphatase and tensin homologue deleted on chromosome 10; BrdU, 5-bromo-2-deoxyuridine; EGF, epidermal growth factor; bFGF, fibroblast growth factor

Key words: neural stem/progenitor cells, microRNA-29, proliferation, PTEN present findings may provide novel insight for the development of strategies for stem cell-mediated treatment of CNS diseases.

\section{Introduction}

Neural stem/progenitor cells (NSPCs) are self-renewing, multipotent cells that generate the neurons, astrocytes and oligodendrocytes of the nervous system. They are present not only in developing, but also in the adult central nervous system (CNS) (1). Neurogenesis occurs mainly in two areas: The subgranular zone of the dentate gyrus and the anterior part of the subventricular zone along the ventricle (2). NSPCs can be activated in response to brain injury, contributing towards the repair and motor functional recovery of the CNS (3). A number of factors regulate the maintenance, activation, and fate choice of NSPCs, including extracellular signaling molecules [basic fibroblast growth factor (bFGF), epidermal growth factor (EGF), glutamate], intracellular signal molecules (GLI family zinc finger 1, AKT, Notch1) and microRNAs (miRNAs/miRs) (4).

miRNAs are small noncoding RNA molecules ( 22 nucleotides) present in plants, animals and certain viruses, which contribute to the post-transcriptional regulation of gene expression by binding and silencing target RNAs, and thus regulate cell behavior (5). Among them, miR-29 is notable due to its regulatory role in cell proliferation, differentiation and survival, not only in cancer cells but also in stem/progenitors cells $(6,7)$. Previous studies have indicated that miR-29 may serve an important role in regulating the behavior of stem cells $(8,9)$; however, the effects of miR-29 on NSPCs and the underlying intracellular signaling mechanisms remain unknown.

In the present study, the effects of miR-29 on proliferation in NSPCs were investigated. It was demonstrated that overexpression of miR-29 promoted NSPC proliferation and inhibited the expression of phosphatase and tensin homologue deleted on chromosome 10 (PTEN) protein, potentially via a mechanism involving the AKT signaling pathway. This research may provide novel insight for the development of strategies for stem cell-mediated treatment of CNS diseases.

\section{Materials and methods}

Rat NSPCs culture. Rat NSPCs were prepared from E14.5 Sprague-Dawley rat embryos as previously described, with 
minor modifications (10). A total of six pregnant rats were used for this study, and five or six embryos obtained from each pregnant rat were used for NSPCs culture. For NSPC culture, the serum-free complete medium consisted of DMEM/F12 (1:1), 1\% N-2 (cat. no. 17502048), 2\% B27 (cat. no. 17504044), $20 \mathrm{ng} / \mathrm{ml} \mathrm{EGF}$ and $10 \mathrm{ng} / \mathrm{ml} \mathrm{Bfgf}$ (10). HepG2 cells, obtained from ATCC (HB-8065), were cultured in DMEM medium (Hyclone; GE Healthcare Life Sciences), supplemented with $10 \%$ fetal bovine serum (Invitrogen; Thermo Fisher Scientific, Inc.). All the cells were incubated at $37^{\circ} \mathrm{C}$ and $5 \% \mathrm{CO}_{2}$ in a humidity incubator (Sanyo Electric Co., Ltd.). After three to five days, cells that multiplied in primary neurospheres (P0 cells) with the a diameter of approximately 90-150 $\mu \mathrm{m}$ were dissociated into single cells by trypsin (0.05\%, Invitrogen; Thermo Fisher Scientific, Inc.). All materials used for cell culture were purchased from Thermo Fisher Scientific, Inc. For single-cell adhesive culture, single NSPCs in serum-free complete medium were allowed to attach onto poly-D-lysine-coated coverslips. For NSPCs differentiation, single cells were cultured in differentiation medium, which removing mitogens (bFGF and EGF) and contained $1 \%$ fetal bovine serum. Following culture for 3 days, cell were fixed by $4 \%$ paraformaldehyde at room temperature for $30 \mathrm{~min}$ and used for immunostaining test.

Pregnant SD rats were purchased from the Experimental Animal Center of Xi'an Jiaotong University Health Science Center (certificate no. 22-9601018). All experimental protocols were approved by the Animal Care and Use Regulation of Xi'an Jiaotong University Health Science Center. All efforts were made to minimize animals' suffering and reduce the number of animals used to a minimum.

Transfection. Cells were plated in poly-D-lysine-coated 24 -well or 6-well plates. Cells were $70-90 \%$ confluent at the time of transfection, and transient transfections were performed using Lipofectamine ${ }^{\circledR} 2000$ (Invitrogen; Thermo Fisher Scientific, Inc.) according to the manufacturer's protocols. The miR-NC, miR-29 mimic and miR-29 inhibitor were purchased from Shanghai GenePharma Co., Ltd. The target sequences were as follows: miR-29 mimic: 5'-ACUGAUUUC UUUUGGUGUUCAG-3'; miR-29 inhibitor: 5'-ACTGAT TTCAAATGGTGCT-3'; miR-NC: 5'-UUCUCCGAACGU GUCACGUTT-3'. Before transfection, the culture medium was washed three times by Opti-MEM (Invitrogen; Thermo Fisher Scientific, Inc.). Cells were transfected with $100 \mathrm{nM}$ microRNA for $6 \mathrm{~h}$ in the presence of Lipofectamine ${ }^{\circledR} 2000$ according to the manufacturer's instructions (Invitrogen; Thermo Fisher Scientific, Inc.). Control treatment involved addition of an equivalent volume of medium without miRNA. Knockdown of mGluR4 expression was further evaluated using reverse transcription (RT) PCR. Cells were cultured for 24 more hours before further treatments.

RT-quantitative PCR (RT-qPCR). After transfection for $24 \mathrm{~h}$, total RNA was isolated using TRIzol reagent (Invitrogen; Thermo Fisher Scientific, Inc.) according to the manufacturer's instructions. RT was performed using TaqMan ${ }^{\circledR}$ MicroRNA Reverse Transcription kit and specific primers (Applied Biosystems; Thermo Fisher Scientific, Inc.). All RT reactions were carried out in triplicates in Mastercycler ep gradient $\mathrm{S}$
(Eppendorf). RT was carried out in an MJ Research Thermal Cycler (Bio-Rad Laboratories) at $16^{\circ} \mathrm{C}$ for $30 \mathrm{~min}, 42^{\circ} \mathrm{C}$ for $30 \mathrm{~min}$, and $85^{\circ} \mathrm{C}$ for $5 \mathrm{~min}$.qPCR was performed using single tube TaqMan ${ }^{\circledR}$ MicroRNA Assays and TaqMan ${ }^{\circledR} 2 \mathrm{X}$ Universal polymerase chain reaction PCR Master Mix, No AmpErase ${ }^{\circledR} \mathrm{UNG}$ (Applied Biosystems; Thermo Fisher Scientific, Inc.) in $10 \mu \mathrm{l}$ reactions. All qPCR reactions were performed in triple in iQ5 Real-Time PCR Detection System (Bio-Rad Laboratories, Inc.). According to the manufacturer's protocol. The primer pairs were synthesized by Takara Biotechnology Co., Ltd. and were as follows: miR-29-forward: 5'-AGTGAATGAGGCCTT CGAGA-3'; miR-29-reverse: 5'-GCATCTGAGTCGCCACT GTA-3'; U6-forward: 5'-GCATCTGAGTCGCCACTGTA-3'; U6-reverse: 5'-CGCTTCACGAATTTGCGTGTCAT-3'. The PCR cycles were performed by initial denaturation at $95^{\circ} \mathrm{C}$ for $5 \mathrm{~min}$, then 40 cycles at $95^{\circ} \mathrm{C}$ for $10 \mathrm{sec}$ followed by $60^{\circ} \mathrm{C}$ for $1 \mathrm{~min}$. Data were analyzed using the $2^{-\Delta \Delta \mathrm{Cq}}$ method (11).

Cell viability assay. Cell viability was evaluated as previously described (12) using a Cell Counting Kit-8 (Roche Applied Science) according to the manufacturer's protocols. For the miR-29 group, NSPCs were grown in 24-well plates, the other groups were grown in 96-well plates at 5,000 cells/well for $24 \mathrm{~h}$ before transfection. Cell viability was detected at the end of each treatment $(6,12,24,48$ and $72 \mathrm{~h}$ following transfection) using an Epoch multi-microplate spectrophotometer (Bio-Tek Instruments, Inc.).

Cell culture 5-bromo-2-deoxyuridine (BrdU) incorporation assay. For the cell proliferation assay, $10 \mu \mathrm{M} \mathrm{BrdU}$ (Sigma-Aldrich; Merck KGaA) solutions were added to NSPCs $\left(1 \times 10^{5}\right.$ cells) plated on coverslips for $2 \mathrm{~h}$. The cells were then fixed with $4 \%$ paraformaldehyde for $30 \mathrm{~min}$ at room temperature. The BrdU-labeled cells were visualized via immunostaining as described below, and stained using propidium iodide $(10 \mu \mathrm{g} / \mathrm{ml}$, Sigma-Aldrich; Merck KGaA) at $37^{\circ} \mathrm{C}$ for $30 \mathrm{~min}$. Immunoreactive cells were observed using a BX51 fluorescent microscope equipped with a DP70 digital camera (Olympus Corporation). Cells from 5 randomly selected fields on each coverslip were counted at x200 magnification. The experiments were performed in triplicates and repeated independently at least three times. The percentage of labeled cells was evaluated and normalized by the PI staining nuclei. All of the counts were conducted on Image-Pro Plus software (version 5.0; Media Cybernetics, Inc.).

Immunostaining. Immunostaining was performed as previously described (13). Briefly, NSCs were fixed in 4\% PFA for $30 \mathrm{~min}$ at room temperature and washed twice with PBS, at the end of treatments. Cells were permeabilized in $0.3 \%$ Triton X-100 and blocked for $1 \mathrm{~h}$ in $10 \%$ normal donkey serum. Then the cells were incubated overnight using the primary antibodies at appropriate dilution (Table I). After thorough rinsing, the cells were detected for $2 \mathrm{~h}$ at room temperature by appropriate Alexa Fluor 488 or 594 conjugated secondary antibodies (Invitrogen; Thermo Fisher Scientific, Inc.). Nuclei were counterstained using DAPI $(1 \mu \mathrm{g} / \mathrm{ml})$. Fluorescence images were observed using a BX51 fluorescent microscope equipped with a DP70 digital camera. For quantification, images were imported into Image-Pro Plus software. Cells from 5 randomly 
Table I. Antibodies used during the study.

\begin{tabular}{|c|c|c|c|c|}
\hline Antigen & Supplier & $\begin{array}{l}\text { Antibody } \\
\text { type }\end{array}$ & $\begin{array}{l}\text { Catalogue } \\
\text { number }\end{array}$ & Dilution \\
\hline Nestin & Merck KGaA & Mouse monoclonal & MAB353 & $1: 200$ in PBS (IF) \\
\hline Tuj1 & Merck KGaA & Mouse monoclonal & MAB1637 & $1: 200$ in PBS (IF) \\
\hline GFAP & Abcam & Rabbit monoclonal & ab33922 & $1: 200$ in PBS (IF) \\
\hline BrdU & Abcam & Sheep polyclonal & ab1893 & $1: 200$ in PBS (IF) \\
\hline $\begin{array}{l}\text { Anti-Mouse } \operatorname{IgG}(\mathrm{H}+\mathrm{L}) \text { secondary } \\
\text { Antibody, Alexa Fluor } 488\end{array}$ & $\begin{array}{l}\text { Donkey polyclonal } \\
\text { antibody }\end{array}$ & Invitrogen & R37114 & 1:500 in PBS (IF) \\
\hline $\begin{array}{l}\text { Anti-Rabbit } \operatorname{IgG}(\mathrm{H}+\mathrm{L}) \text { secondary } \\
\text { Antibody, Alexa Fluor } 594\end{array}$ & $\begin{array}{l}\text { Donkey polyclonal } \\
\text { antibody }\end{array}$ & Invitrogen & R37119 & 1:500 in PBS (IF) \\
\hline $\begin{array}{l}\text { Anti-Sheep IgG }(\mathrm{H}+\mathrm{L}) \text { Cross-Adsorbed } \\
\text { Secondary Antibody }\end{array}$ & $\begin{array}{l}\text { Donkey polyclonal } \\
\text { antibody }\end{array}$ & Invitrogen & A-11016 & 1:500 in PBS (IF) \\
\hline PTEN & $\begin{array}{l}\text { Cell Signaling } \\
\text { Technology, Inc. }\end{array}$ & Rabbit polyclonal & 9188 & 1,1000 in TBST (WB) \\
\hline $\mathrm{p}-\mathrm{AKT}$ & $\begin{array}{l}\text { Cell Signaling } \\
\text { Technology, Inc. }\end{array}$ & Rabbit polyclonal & 9271 & 1,1000 in TBST (WB) \\
\hline AKT & $\begin{array}{l}\text { Cell Signaling } \\
\text { Technology, Inc. }\end{array}$ & Rabbit polyclonal & 9272 & 1,1000 in $\mathrm{TBST}(\mathrm{WB})$ \\
\hline$\beta$-actin & $\begin{array}{l}\text { Sigma-Aldrich } \\
(\text { Merck KGaA) }\end{array}$ & Mouse polyclonal & A1978 & 1,1000 in TBST (WB) \\
\hline
\end{tabular}

Tuj1, neuron-specific class III $\beta$-tubulin, GFAP, glial fibrillary acidic protein; BrdU, 5-bromo-2-deoxyuridine; PTEN, phosphatase and tensin homologue deleted on chromosome 10; p-, phosphorylated; IF, immunofluorescence; WB, western blotting; TBST, TBS-Tween-20.

selected fields on each coverslip were counted at x400 magnification. The experiments were performed in triplicates and repeated independently at least three times.

Cell cycle analysis. The cell cycle was analyzed using fluorescence activated cell sorting as previously described (13). Briefly, NSPCs were fixed using ice-cold $75 \%$ ethanol overnight at $4^{\circ} \mathrm{C}$. After washing in PBS, the cells were stained with $100 \mu \mathrm{g} / \mathrm{ml}$ Propidium iodide containing $100 \mu \mathrm{g} / \mathrm{ml}$ RNase A for $30 \mathrm{~min}$ at $37^{\circ} \mathrm{C}$ in dark. Samples were analyzed using a flow cytometer (FACSCalibur; BD Biosciences), and DNA contents and cell cycle distribution were determined using Modfit LT software (version 3.2, BD Biosciences). The proliferation index (PI) used to evaluate differences in the cell cycle distribution was calculated as follows: $\mathrm{PI}=\left(\mathrm{S}+\mathrm{G}_{2} / \mathrm{M}\right) /\left[\mathrm{G}_{0} / \mathrm{G}_{1}+\left(\mathrm{S}+\mathrm{G}_{2} / \mathrm{M}\right)\right]$.

Western blot analysis. Western blotting was performed as previously described (13). Briefly, NSPCs were grown in 6-well plates at $2 \times 10^{5}$ cells/well for 24 hours prior to the experiments. After transfection, NSPCs protein were collected at the end of each treatment $(5,15,30,60$ and $120 \mathrm{~h})$. The effects of miR-29 on NSPCs were further confirmed by blockade of PTEN using antagonist VO-OHpic trihydrate (VU-OH, $5 \mu \mathrm{M}$, Abcam). Before transfection $24 \mathrm{~h}, 2 \mu \mathrm{M}$ VO-OH were added in the anti-miR-29 group medium and still contained $\mathrm{VO}-\mathrm{OH}$ in the medium after transfection. Because $\mathrm{VO}-\mathrm{OH}$ were dissolved in DMSO, the same volume of DMSO were added in the control group as negative group. After $30 \mathrm{~h}$, NSPCs protein were collected and used for western blot. Protein concentration was determined using the BCA method (Pierce) and lysates
(20-40 $\mu \mathrm{g} / \mathrm{sample}$ ) were subjected to $12 \%$ SDS-PAGE, and transferred onto PVDF membranes. Membranes were blocked for $1 \mathrm{~h}$ in $5 \%$ non-fat dry milk in Tris- $\mathrm{HCl}$ buffer followed by incubated in primary antibodies (Table I) overnight at $4^{\circ} \mathrm{C}$. Membranes were then incubated in HRP-conjugated secondary antibody for $1 \mathrm{~h}$ at room temperature. Following a thorough rinse, Immunoreactive bands were detected using an enhanced chemiluminescent (ECL) substrate (Pierce; Thermo Fisher Scientific, Inc.) and exposure to a Fuji X-ray film (Fujian Gutian Yuanhang Medical Co., Ltd.). Bands were imaged using a G:Box gel imaging system (Syngene), and protein expression quantified using ImageJ 3.5 software (National Institutes of Health).

Statistical analysis. Data were presented as the mean \pm standard deviation from at least three independent in vitro experiments. Differences between groups were analyzed using one-way ANOVA, followed by Tukey's post hoc test. All statistical analyses were performed using SPSS version 12.0 software (SPSS, Inc.). $\mathrm{P}<0.05$ was considered to indicate a statistically significant difference.

\section{Results}

Characterization of NSPCs derived from fetal rat cortex. Primary NSPCs were cultured as aforementioned. After 2-3 days, NSPCs proliferated and formed secondary neurospheres (Fig. 1A), and were characterized by expression of nestin (a marker of NSPCs). Nestin-positive immunoreactivity was observed in $88.02 \pm 4.39 \%$ of cells in the neurospheres 

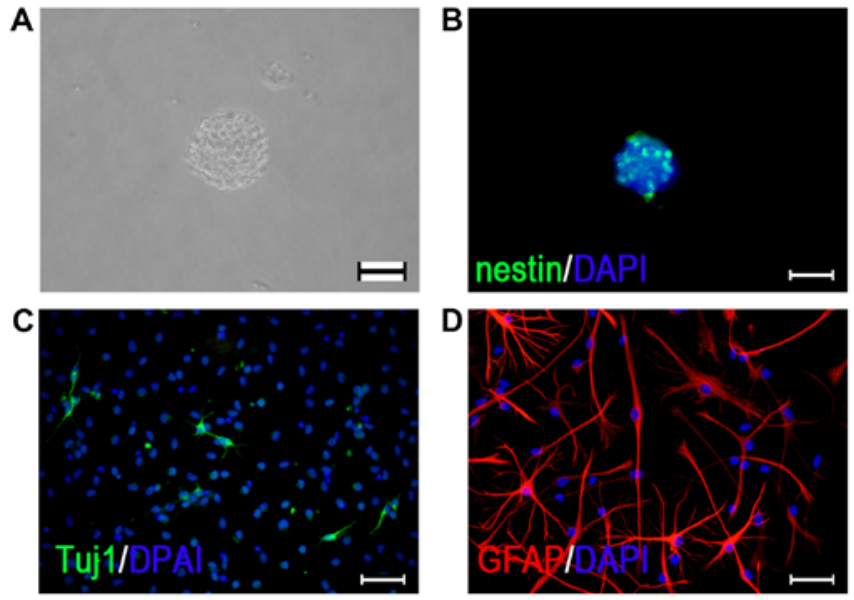

E

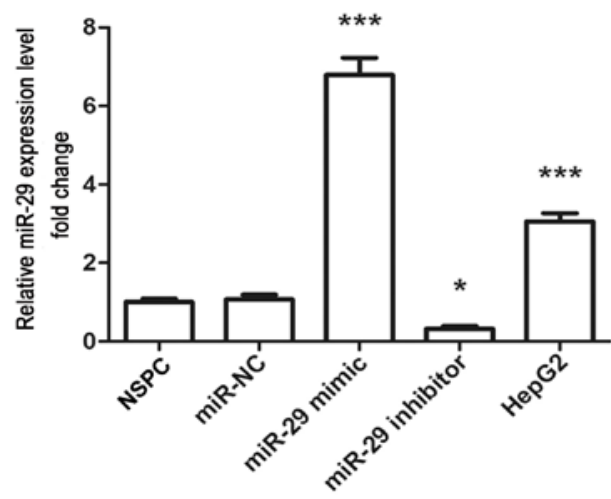

Figure 1. Culture and immunocytochemical characterization of fetal ra cortex NSPCs. (A) NSPCs were isolated from the E14.5 fetal rat cortex, and neurospheres were formed following 3-5 days of cell proliferation. Scale bar, $200 \mu \mathrm{m}$. (B) Nestin (green) immunostaining of NSPCs was conducted in neurospheres under proliferating conditions. Scale bar, $200 \mu \mathrm{m}$. NSPCs were differentiated into (C) Tuj1- and (D) GFAP-immunopositive cells by removal mitogens and adding $1 \%$ fetal bovine serum. Scale bar, $40 \mu \mathrm{m}$. Nuclei were counterstained with DAPI (blue). (E) Reverse transcription-quantitative PCR analysis indicated that miR-29 mimic increased the expression of miR-29, whereas miR-29 inhibitor downregulated its expression. The liver cancer cell line HepG2 was used as a positive control. ${ }^{*} \mathrm{P}<0.05,{ }^{* * * *} \mathrm{P}<0.001$ vs. miR-NC NSPC, neural stem/progenitor cell; miR-29, microRNA-29; miR-NC, microRNA negative control; Tuj1, neuron-specific class III $\beta$-tubulin; GFAP, glial fibrillary acidic protein.

(Fig. 1B). To identify the neural differentiating potential, the NSPCs were dissociated into single cells by trypsin, plated onto poly-D-lysine-coated coverslips and cultured in differentiating medium (DMEM/F12 supplemented with 1\% N2, 2\% B27 and $1 \%$ FBS, lacking bFGF and EGF). Immunostaining revealed that neuron-specific class III $\beta$-tubulin (Tuj1; a marker of immature neurons) and glial fibrillary acidic protein (a marker of astrocytes) immunoreactivity was observed in cultured cells (Fig. 1C and D).

miR-29 promotes the viability of NSPCs. To investigate the effects of miR-29 on NSPCs, cells were transfected with miR-NC, miR mimic or inhibitor. It was revealed that transfection with miR mimic significantly upregulated the expression of miR-29 compared with miR-NC, whereas miR-29 inhibitor significantly downregulated expression (Fig. 1E). Then, CCK-8 assays were conducted at various timepoints following transfection of NSPCs with miR-NC, miR-29 mimic or miR-29 inhibitor. It was revealed that cell viability was significantly increased at $24 \mathrm{~h}$ following transfection with miR-29 compared with at $0 \mathrm{~h}$, whereas the viability of control and miR-NC-transfected NPSCs was only significantly increased compared with $0 \mathrm{~h}$ at the 48 -h point (Fig. 2A-C). Conversely, the viability of miR-29 inhibitor-transfected cells did not significantly alter across the 72-h assay period (Fig. 2D). The results suggested that overexpression of miR-29 promoted the viability of NSPCs.

miR-29 promotes the expression of PTEN. PTEN protein catalyzes the dephosphorylation of the 3'phosphate of the inositol ring of phosphatidylinositol $(3,4,5)$-trisphosphate $\left(\mathrm{PIP}_{3}\right)$, converting it to phosphatidylinositol $(4,5)$-bisphosphate $\left(\mathrm{PIP}_{2}\right)(14)$. A previous study reported that PTEN has a role in regulating NSPC behavior (15). To investigate whether miR-29 influenced the expression of PTEN, NSPCs were transfected with miR-29 mimic or miR-29 inhibitor. Following treatment for various durations $(5,15,30,60$ and $120 \mathrm{~h})$, total protein was collected and PTEN expression was analyzed via western blotting. The results indicated that the overexpression of miR-29 significantly downregulated the expression of PTEN in a time-dependent manner (Fig. 3A). Of note, knockdown of miR-29 induced opposing effects on the expression of PTEN (Fig. 3B). To further investigate the effects of miR-29 on PTEN, VO-OHpic trihydrate (VO-OH; a potent, selective and reversible PTEN inhibitor) was added to the culture medium. NSPCs were transfected with miR-NC, miR-29 mimic or miR-29 inhibitor; miR-29 inhibitor-treated cells were pretreated with $2 \mu \mathrm{M}$ VO-OH. As VO-OH was dissolved in DMSO, the same volume of DMSO $(0.5 \%)$ was added to the control group as a negative control group. There were no significant differences observed between the control, DMSO and miR-NC groups, indicating that DMSO and miR-NC did not influence the expression of PTEN. miR-29 mimic-transfected cells exhibited significantly downregulated expression of PTEN, whereas miR-29 inhibitor upregulated PTEN expression. Of note, treatment with VO-OH significantly eliminated the effects of anti-miR-29 on PTEN levels (Fig. 3C). It is hypothesized that a possible reason for PTEN suppression is that VO-OH (a highly potent inhibitor of PTEN) could inhibit the activation of AKT pathway, which may feedback to PTEN and suppress the PTEN expression. The results indicated that miR-29 regulated the expression of PTEN in NSPCs, and that overexpression of miR-29 inhibited the expression of PTEN.

Additionally, the activation of AKT (a kinase downstream of PTEN) was analyzed via western blotting. Overexpression of miR-29 promoted the phosphorylation of AKT, whereas knockdown of miR-29 induced opposing effects (Fig. 3D). Furthermore, VO-OH significantly attenuated the effects of miR-29 inhibitor on AKT activation. The findings indicated that miR-29 affected the activation of the AKT signaling pathway.

miR-29 promotes the proliferation of NSPCs by regulating $P T E N$. To investigate whether the effects of miR-29 on the proliferation of cells were mediated by PTEN, BrdU and cell cycle assays were conducted in the presence of $\mathrm{VO}-\mathrm{OH}$. NSPCs were transfected as described. BrdU staining analysis revealed that both DMSO and miR-NC did not significantly affect the proliferation of NSPCs compared with the control 

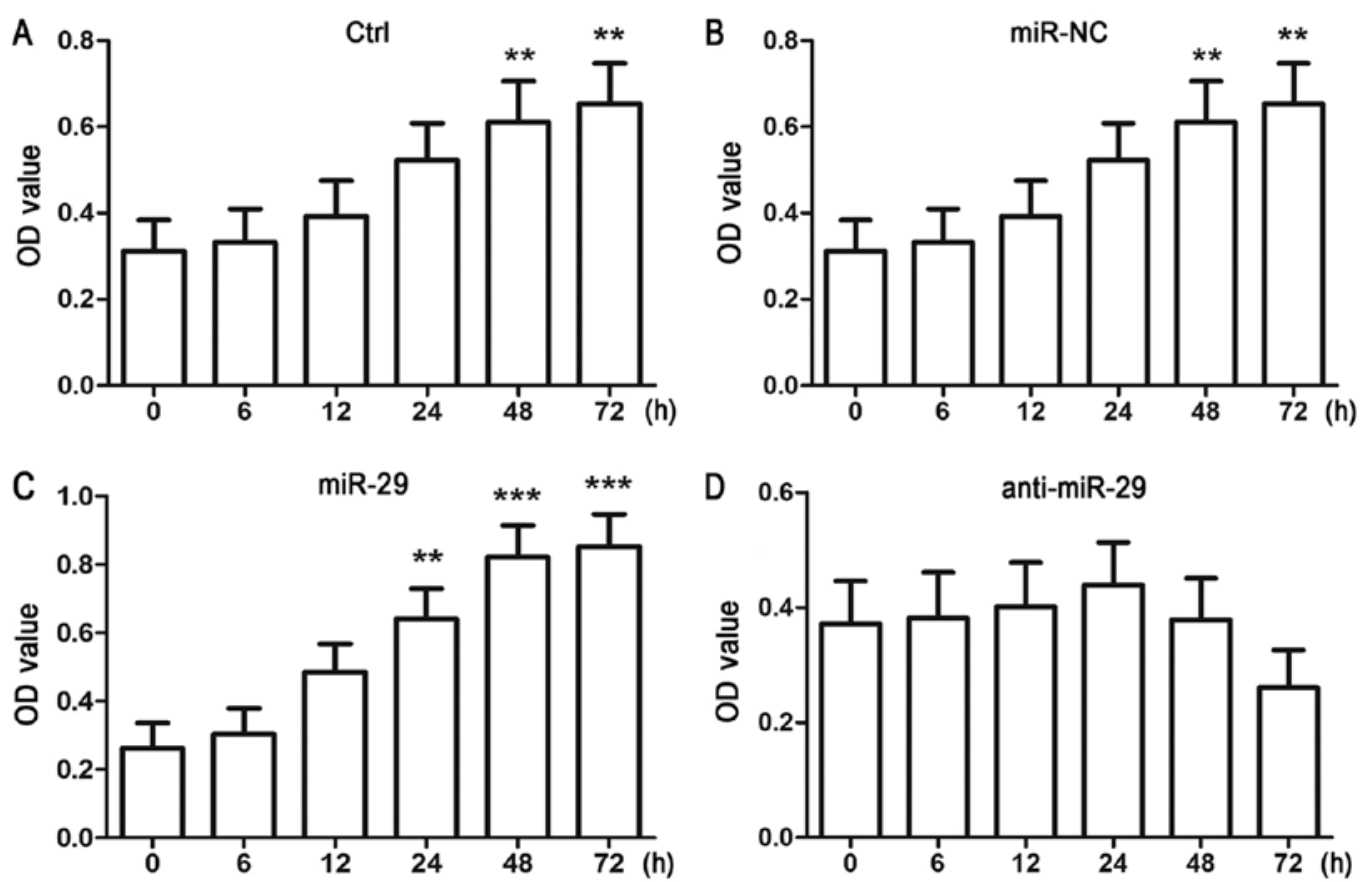

Figure 2. Overexpression of miR-29 increases the viability of cultured NSPCs. Single adhesive cultured NSPCs were transfected for $6 \mathrm{~h}$ with (A) Ctrl, (B) miR-NC, (C) miR-29 mimic or (D) anti-miR-29 using Lipofectamine 2000. Cell viability was detected by a Cell Counting Kit-8 assay at the end of each time point $(6,12,24$ and $72 \mathrm{~h})$. Data are presented as the mean \pm standard deviation of three independent experiments. ${ }^{* * *} \mathrm{P}<0.01,{ }^{* * * *} \mathrm{P}<0.001 \mathrm{vs} .0 \mathrm{~h}$. NSPC, neural stem/progenitor cell; miR-29, microRNA-29; anti-miR-29, miR-29 inhibitor; miR-NC, microRNA negative control; Ctrl, miR-free medium; OD, optical density.

(Fig. 4A and B). Conversely, overexpression of miR-29 significantly increased the number of BrdU-positive cells compared with the control, whereas knockdown of miR-29 induced opposing effects; however, treatment with $\mathrm{VO}-\mathrm{OH}$ significantly eliminated the effects of miR-29 inhibitor on the number of BrdU-positive cells (Fig. 4A and B). The results of the cell cycle assay were similar to those from the BrdU assay. Overexpression of miR-29 significantly increased the PI of NSPCs compared with the control, whereas knockdown of miR-29 decreased the PI, an effect that was significantly reversed by treatment with VO-OH (Fig. 4C). Collectively, these results suggested that miR-29 promoted the proliferation of NSPCs in a PTEN-dependent manner.

\section{Discussion}

PTEN protein is one of the most frequently mutated tumor suppressor genes in human cancer; however, previous studies reported that PTEN serves important roles not only in cancer cells, but also in NSPCs $(15,16)$. Such findings suggest that PTEN could be potential novel treatments to promote CNS repair. A number of factors regulate the intracellular expression of PTEN, including miR-29; previous studies demonstrated that miR-29 significantly downregulated the expression of PTEN in various types of cell (17-19). However, the effects of miR-29 on PTEN in NSPCs remain unclear. In the present study, it was demonstrated that overexpression of miR-29 decreased PTEN expression in a time-dependent manner, and that PTEN inhibitor eliminated the effects of miR-29 inhibitor. Furthermore, the results indicated that miR-29 promoted NPSC proliferation by inhibiting the expression of PTEN. These findings suggested that miR-29 may be a molecular target for regulating the proliferation of NSPCs.

It was previously demonstrated that PTEN protein exhibits at least two biochemical functions: It has both lipid phosphatase and protein phosphatase activity (20). As a phosphatase, PTEN protein specifically catalyzes the dephosphorylation of the 3'phosphate on the inositol ring of $\mathrm{PIP}_{3}$, converting it to $\mathrm{PIP}_{2}$. This dephosphorylation leads to the inhibition of the AKT signaling pathway (21). AKT is an important intercellular signal molecule involved in the regulation of the proliferation, differentiation and survival of numerous types of cell, including NSPCs $(22,23)$. Activation of AKT promoted neurogenesis and the proliferation of retinal progenitor cells in vitro and in vivo $(13,23)$. In the present study, it was revealed that overexpression of miR-29 increased the phosphorylation levels of AKT. Furthermore, PTEN arrests cell cycle progression at the $\mathrm{G}_{1} / \mathrm{S}$ phase, mediated at least partially via the upregulation of the cyclin-dependent kinase inhibitor p27 (24). As such, it is proposed that miR-29 may promote the proliferation of NSPCs by suppressing the expression of PTEN protein and thereby promoting the activation of AKT. For protein phosphatase activity, PTEN does not only affect the PI-3-K signaling pathway; it is involved in the persistent enhancement of neural stem cell self-renewal without exhaustion, and the inhibition of the growth factor-stimulated mitogen-activated protein kinase (MAPK) signaling pathway $(25,26)$. The MAPK and AKT signaling pathways contribute to the proliferation of NSPCs, and activation of MAPK signaling pathway may promote cell proliferation (27). Intercellular signaling pathways form an intersecting biochemical network that, once activated, can result in a series of biological effects, including proliferation, apoptosis and differentiation (28). Cross-talk 
A
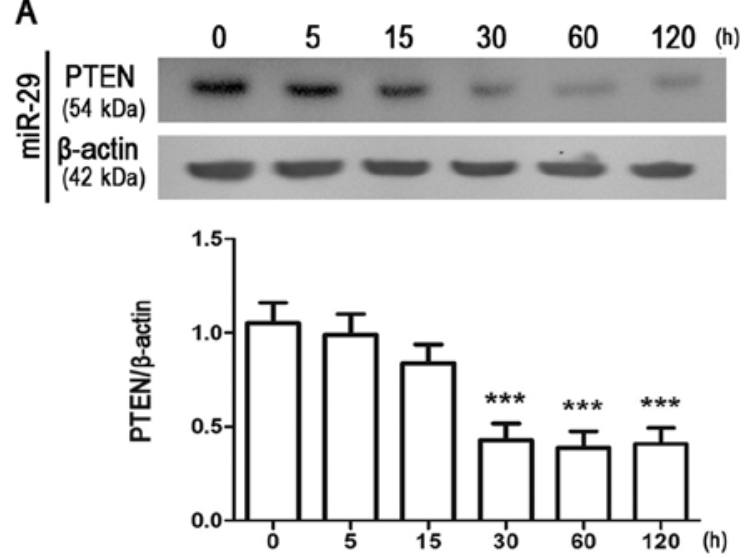

C
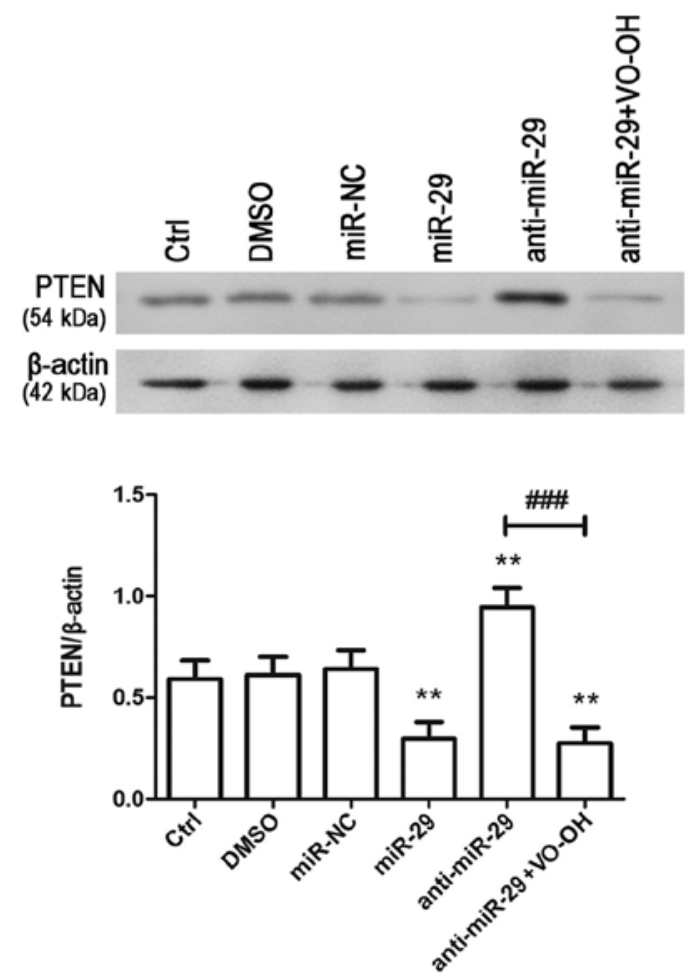

B
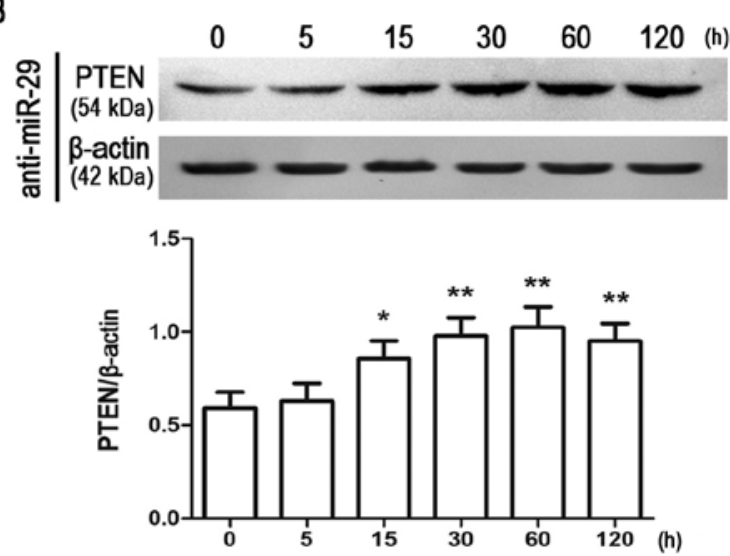

D
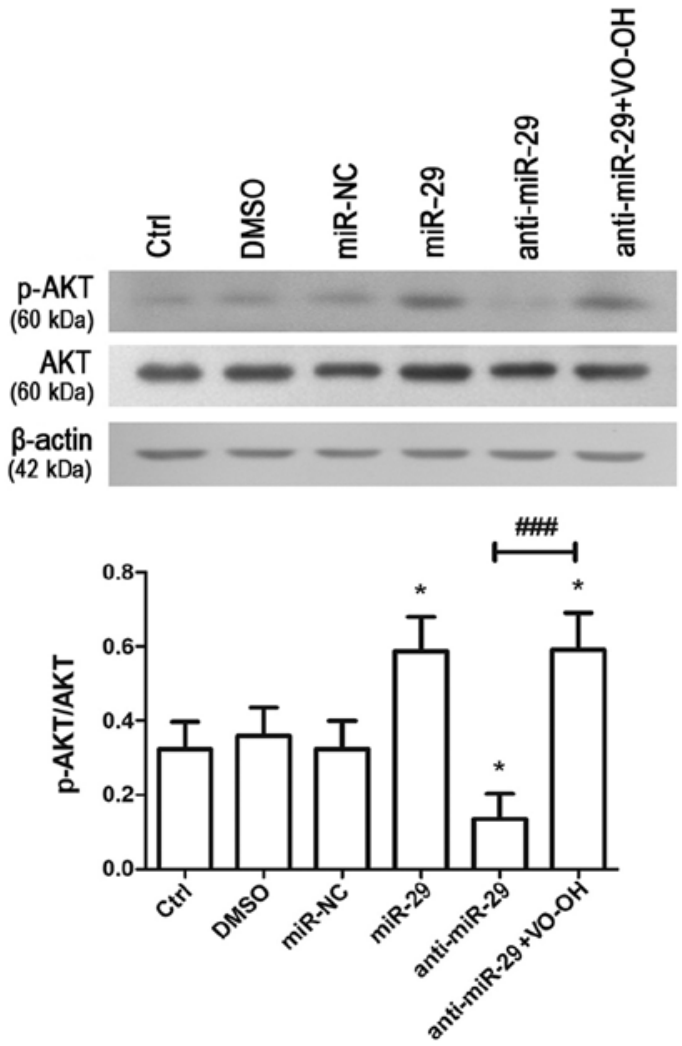

Figure 3. miR-29 regulates the PTEN/AKT signaling pathway in NPSCs. Single adhesive cultured NSPCs were transfected with (A) miR-29 mimic or (B) miR-29 inhibitor using Lipofectamine 2000. After transfection, NSPCs protein were collected at the end of each treatment and detected by western blot analysis after each time point $(5,15,30,60,120 \mathrm{~h})$. Data are presented as the mean \pm standard deviation of three independent experiments. ${ }^{*} \mathrm{P}<0.05$, ${ }^{* *} \mathrm{P}<0.01,{ }^{* * * *} \mathrm{P}<0.001$ vs. 0 h. (C) To further investigate the effects of miR-29 on PTEN, the PTEN-specific inhibitor VO-OH was added to the medium before transfection and the medium after transfection still contained VO-OH. PTEN expression was quantified and normalized to $\beta$-actin. Data are presented as the mean \pm standard deviation of three independent experiments. ${ }^{* *} \mathrm{P}<0.01$ vs. DMSO; ${ }^{\# \#} \mathrm{P}<0.001$ vs. anti-miR-29. (D) Expression of $\mathrm{p}-\mathrm{AKT}$ and AKT as determined by western blot analysis; p-AKT expression was normalized to total AKT expression. Data are presented as the mean \pm standard deviation of three independent experiments. ${ }^{*} \mathrm{P}<0.05$ vs. DMSO, ${ }^{\# \# "} \mathrm{P}<0.001$ vs. anti-miR-29. NSPC, neural stem/progenitor cell; miR-29, microRNA-29; anti-miR-29, miR-29 inhibitor; miR-NC, microRNA negative control; Ctrl, treatment with miRNA-free medium; DMSO, dimethyl sulfoxide; PTEN, phosphatase and tensin homologue deleted on chromosome 10; VO-OH, VO-OHpic trihydrate; p-, phosphorylated.

exists between the kinase cascades, in which the inhibition of one kinase cascade may lead to the activation of another, and vice versa (29). Therefore, whether other signal pathways are involved in the effects of miR-29 on NPSC proliferation requires further investigation.

miR-29 was one of the first miRNAs detected in the human genome, and is upregulated in all types of human malignancy; overexpression of miR-29 may promote proliferation and invasion, and reduce cell apoptosis (30). This previous study showed miR-29 family members share a common seed region sequence and are predicted to target largely overlapping sets of genes. However, the miR-29 family members exhibit differential regulation in several cases and different subcellular distribution, suggesting their functional relevance may not be identical $(30,31)$. It may be one of reason why the function of miR-29 is different between NSPCs and some types of cancer cells. Previous studies demonstrated that miR-29 regulated cell behavior 
A

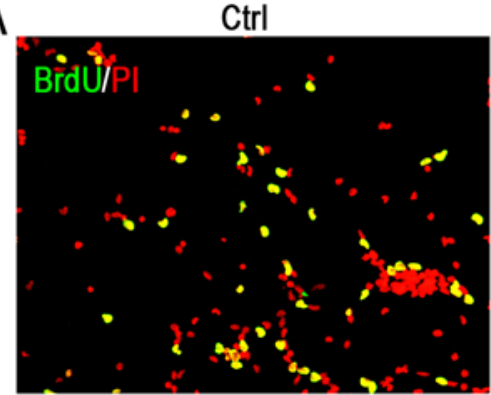

miR-NC

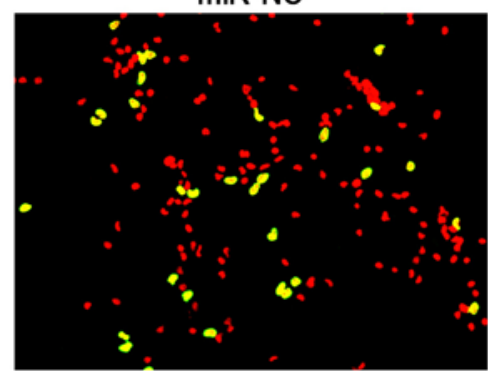

anti-miR-29

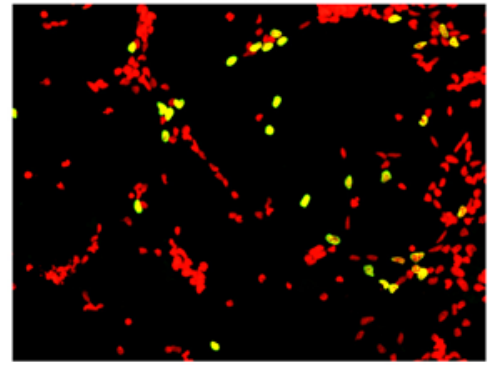

DMSO

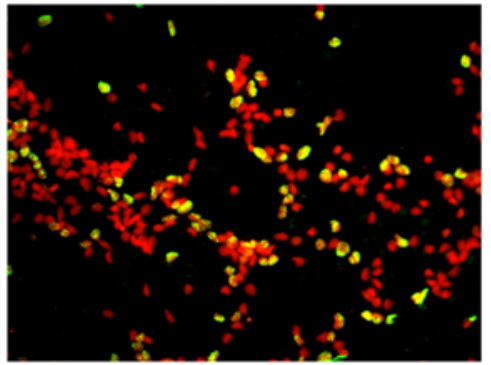

miR-29

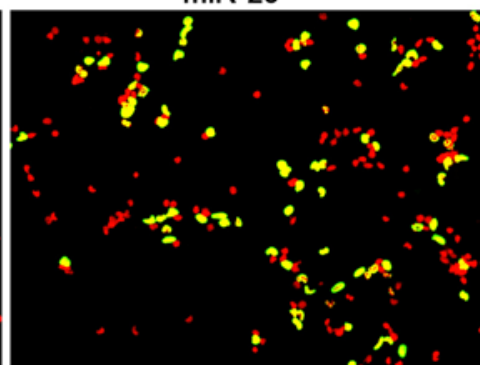

anti-miR-29+VO-OH

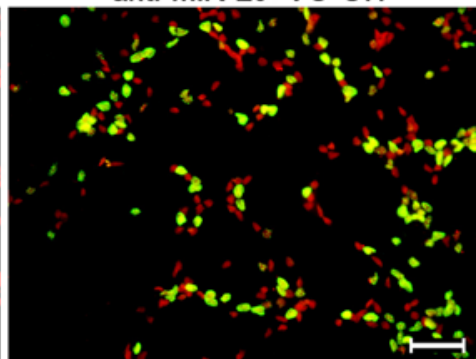

B
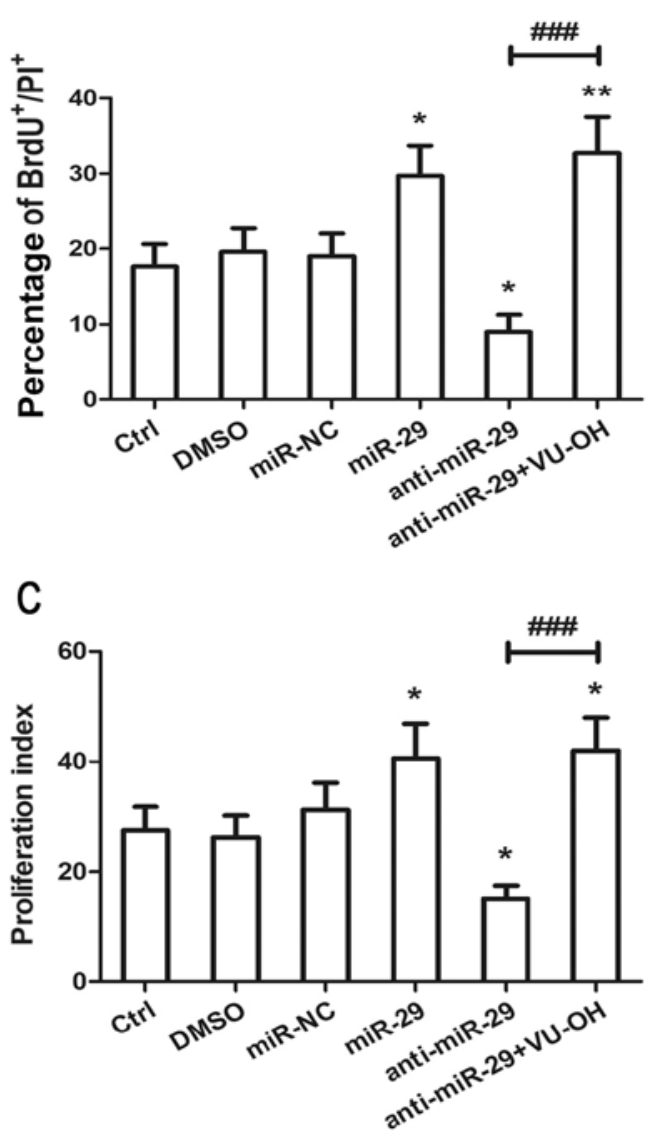

Figure 4. Overexpression of miR-29 promotes the proliferation of NSPCs. Single adhesive cultured NSPCs were transfected for 6 h with miR-NC, miR-29 mimic or miR-29 inhibitor using Lipofectamine 2000. In addition, the PTEN-specific inhibitor VO-OH was used to treat anti-miR-29 cells. (A) Proliferating cells were detected by BrdU incorporation and immunostaining. BrdU-labeled cells, green; propidium iodide, red. Scale bars $=200 \mu \mathrm{m}$. (B) Data from three independent experiments $(\mathrm{n}=3)$ are presented as the percentage of BrdU-positive cells in the total population of propidium iodide-positive cells. ${ }^{*} \mathrm{P}<0.05,{ }^{* *} \mathrm{P}<0.01$ vs. DMSO; ${ }^{\# \# \#} \mathrm{P}<0.001$ vs. anti-miR-29. (C) Proliferation index of transfected cells as determined by cell cycle analysis. Proliferation index $=\left(S+\mathrm{G}_{2} / \mathrm{M}\right) /\left[\mathrm{G}_{0} / \mathrm{G}_{1}+\left(\mathrm{S}+\mathrm{G}_{2} / \mathrm{M}\right)\right]$. Data are presented as the mean \pm standard deviation of three independent experiments. * $\mathrm{P}<0.05$ vs. DMSO group;

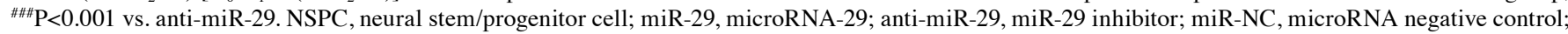
Ctrl, treatment with miRNA-free medium; DMSO, dimethyl sulfoxide; PTEN, phosphatase and tensin homologue deleted on chromosome 10; VO-OH, VO-OHpic trihydrate; $\mathrm{p}-$, phosphorylated.

not only by regulating the expression of PTEN protein; a number of tumor-suppressor genes have also been identified as targets for miR-29, supporting its proposed pro-proliferative role in cells (31). These genes include various components of the p53 network, c-Myc and Smad, all of which are involved in tumorigenesis, cell cycle control and apoptosis $(32,33)$. Additionally, an increasing number of miR-29 targets are being identified, and novel regulatory mechanisms of miR-29 are being determined. Therefore, it is possible that the effects of miR-29 on the proliferation of NSPCs were mediated by other targets, in addition to or instead of PTEN. The present study reported that overexpression of miR-29 increased the viability of NPSCs and reduced the expression of PTEN. The proliferation of NSPCs was further promoted by miR-29, as indicated by increases in the number of BrdU-positive cells and the PI. Of note, VO-OH, a PTEN-specific inhibitor, attenuated the anti-proliferative effects of miR-29 inhibitor on NSPCs. Furthermore, the proliferation effects of miR-29 might be due to suppression the expression of PTEN in cultured rat NSPCs. These data may provide a theoretical basis and reference for the clinical treatment of CNS diseases. However, additional research must be conducted to explain the precise mechanism by which miR-29 promotes proliferation of NSPCs.

\section{Acknowledgements}

Not applicable.

\section{Funding}

This work was supported by the National Natural Science Foundation of China (grant no. 81000030) and Fundamental Research funds for the Central Universities (grant no. xzy012019104).

\section{Availability of data and materials}

The datasets used and/or analyzed during the current study are available from the corresponding author on reasonable request. 


\section{Authors' contributions}

YG, HQ and YH designed the experiments. YH supervised the research. YG, HQ and ZL performed most of experiments. YG drafted the manuscript. HQ and YH revised the manuscript. All authors read and approved the final manuscript.

\section{Ethics approval and consent to participate}

All experimental protocols were approved by the Animal Care and Use Regulation of Xi'an Jiaotong University Health Science Center.

\section{Patient consent for publication}

Not applicable.

\section{Competing interests}

The authors declare that they have no competing interests.

\section{References}

1. Bond AM, Ming GL and Song H: Adult mammalian neural stem cells and neurogenesis: Five decades later. Cell Stem Cell 17: 385-395, 2015.

2. Taupin P: Adult neurogenesis in the mammalian central nervous system: Functionality and potential clinical interest. Med Sci Monit 11: RA247-RA252, 2005.

3. Zhao C, Deng W and Gage FH: Mechanisms and functional implications of adult neurogenesis. Cell 132: 645-660, 2008.

4. Temple S: The development of neural stem cells. Nature 414: 112-117, 2001.

5. Carthew RW and Sontheimer EJ: Origins and mechanisms of miRNAs and siRNAs. Cell 136: 642-655, 2009.

6. Cui Y, Li T, Yang D, Li S and Le W: miR-29 regulates Tet1 expression and contributes to early differentiation of mouse ESCs. Oncotarget 7: 64932-64941, 2016.

7. Xiong Y, Fang JH, Yun JP, Yang J, Zhang Y, Jia WH and Zhuang SM: Effects of microRNA-29 on apoptosis, tumorigenicity, and prognosis of hepatocellular carcinoma. Hepatology 51 : 836-845, 2010 .

8. Fráguas MS, Eggenschwiler R, Hoepfner J, Schiavinato JL, Haddad R, Oliveira LH, Araújo AG, Zago MA, Panepucci RA and Cantz T: MicroRNA-29 impairs the early phase of reprogramming process by targeting active DNA demethylation enzymes and Wnt signaling. Stem Cell Res 19: 21-30, 2017.

9. Hilz S, Fogarty EA, Modzelewski AJ, Cohen PE and Grimson A: Transcriptome profiling of the developing male germ line identifies the miR-29 family as a global regulator during meiosis. RNA Biol 14: 219-235, 2017.

10. Zhang Z, Ma W, Wang L, Gong H, Tian Y, Zhang J, Liu J, Lu H, Chen X and Liu Y: Activation of type 4 metabotropic glutamate receptor attenuates oxidative stress-induced death of neural stem cells with inhibition of JNK and p38 MAPK signaling. Stem Cells Dev 24: 2709-2722, 2015.

11. Livak KJ and Schmittgen TD: Analysis of relative gene expression data using real-time quantitative PCR and the 2(-Delta Delta C(T)) method. Methods 25: 402-408, 2001.

12. Chen L, Liu M, Luan Y, Liu Y, Zhang Z, Ma B, Liu X and Liu Y: BMP6 protects retinal pigment epithelial cells from oxidative stressinduced injury by inhibiting the MAPK signaling pathways. Int J Mol Med 42: 1096-1105, 2018.

13. Zhang Z, Hu F, Liu Y, Ma B, Chen X, Zhu K, Shi Y, Wei T, Xing Y, Gao Y, et al: Activation of type 5 metabotropic glutamate receptor promotes the proliferation of rat retinal progenitor cell via activation of the PI-3-K and MAPK signaling pathways. Neuroscience 322: 138-151, 2016.

14. Yuan TL and Cantley LC: PI3K pathway alterations in cancer: Variations on a theme. Oncogene 27: 5497-5510, 2008.
15. Zheng H, Ying H, Yan H, Kimmelman AC, Hiller DJ, Chen AJ, Perry SR, Tonon G, Chu GC, Ding Z, et al: p53 and Pten control neural and glioma stem/progenitor cell renewal and differentiation. Nature 455: 1129-1133, 2008.

16. Cao L, Liu P, Gill K, Reece EA, Cheema AK and Zhao Z: Identification of novel cell survival regulation in diabetic embryopathy via phospholipidomic profiling. Biochem Biophys Res Commun 470: 599-605, 2016

17. Lin X, Zhou X, Liu D, Yun L, Zhang L, Chen X, Chai Q and Li L: MicroRNA-29 regulates high-glucose-induced apoptosis in human retinal pigment epithelial cells through PTEN. In Vitro Cell Dev Biol Anim 52: 419-426, 2016.

18. Zanotti S, Gibertini S, Curcio M, Savadori P, Pasanisi B, Morandi L, Cornelio F, Mantegazza R and Mora M: Opposing roles of miR-21 and miR-29 in the progression of fibrosis in Duchenne muscular dystrophy. Biochim Biophys Acta 1852: 1451-1464, 2015.

19. Zou H, Ding Y, Shi W, Xu X, Gong A, Zhang Z and Liu J: MicroRNA-29c/PTEN pathway is involved in mice brain development and modulates neurite outgrowth in PC12 cells. Cell Mol Neurobiol 35: 313-322, 2015.

20. Tamguney T and Stokoe D: New insights into PTEN. J Cell Sci 120: 4071-4079, 2007.

21. Janku F, Hong DS, Fu S, Piha-Paul SA, Naing A, Falchook GS, Tsimberidou AM, Stepanek VM, Moulder SL, Lee JJ, et al: Assessing PIK3CA and PTEN in early-phase trials with PI3K/AKT/mTOR inhibitors. Cell Rep 6: 377-387, 2014.

22. Kondo T, Funayama M, Tsukita K, Hotta A, Yasuda A, Nori S, Kaneko S, Nakamura M, Takahashi R, Okano H, et al: Focal transplantation of human iPSC-derived glial-rich neural progenitors improves lifespan of ALS mice. Stem Cell Reports 3: 242-249, 2014.

23. Le Belle JE, Orozco NM, Paucar AA, Saxe JP, Mottahedeh J, Pyle AD, Wu H and Kornblum HI: Proliferative neural stem cells have high endogenous ROS levels that regulate self-renewal and neurogenesis in a PI3K/Akt-dependant manner. Cell Stem Cell 8: 59-71, 2011

24. Wu H, Goel V and Haluska FG: PTEN signaling pathways in melanoma. Oncogene 22: 3113-3122, 2003.

25. Gregorian C, Nakashima J, Le Belle J, Ohab J, Kim R, Liu A, Smith KB, Groszer M, Garcia AD, Sofroniew MV, et al: Pten deletion in adult neural stem/progenitor cells enhances constitutive neurogenesis. J Neurosci 29: 1874-1886, 2009.

26. Mulholland DJ, Kobayashi N, Ruscetti M, Zhi A, Tran LM, Huang J, Gleave $\mathrm{M}$ and $\mathrm{Wu} \mathrm{H}$ : Pten loss and RAS/MAPK activation cooperate to promote EMT and metastasis initiated from prostate cancer stem/progenitor cells. Cancer Res 72: 1878-1889, 2012.

27. Huang X, Zhu LL, Zhao T, Wu LY, Wu KW, Schachner M, Xiao ZC and Fan M: CHL1 negatively regulates the proliferation and neuronal differentiation of neural progenitor cells through activation of the ERK1/2 MAPK pathway. Mol Cell Neurosci 46: 296-307, 2011.

28. Torsvik A and Bjerkvig R: Mesenchymal stem cell signaling in cancer progression. Cancer Treat Rev 39: 180-188, 2013.

29. Hausenloy DJ, Mocanu MA and Yellon DM: Cross-talk between the survival kinases during early reperfusion: Its contribution to ischemic preconditioning. Cardiovasc Res 63: 305-312, 2004

30. Kriegel AJ, Liu Y, Fang Y, Ding X and Liang M: The miR-29 family: Genomics, cell biology, and relevance to renal and cardiovascular injury. Physiol Genomics 44: 237-244, 2012.

31. Wang Y, Zhang X, Li H, Yu J and Ren X: The role of miRNA-29 family in cancer. Eur J Cell Biol 92: 123-128, 2013.

32. He Y, Huang C, Lin X and Li J: MicroRNA-29 family, a crucial therapeutic target for fibrosis diseases. Biochimie 95: 1355-1359, 2013.

33. Yan B, Guo Q, Fu FJ, Wang Z, Yin Z, Wei YB and Yang JR: The role of miR-29b in cancer: Regulation, function, and signaling. Onco Targets Ther 8: 539-548, 2015.

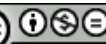

This work is licensed under a Creative Commons Attribution-NonCommercial-NoDerivatives 4.0 International (CC BY-NC-ND 4.0) License. 